\title{
Analysis of the Hybrid Power System for High-Altitude Unmanned Aircraft
}

\author{
Kangwen Sun, Ming Zhu, Lifeng Wang, and Hu Liu \\ School of Aeronautic Science and Technology, Beihang University, Beijing 100191, China \\ Correspondence should be addressed to Ming Zhu; zm_buaa@163.com
}

Received 23 February 2015; Accepted 3 June 2015

Academic Editor: Santiago Garcia-Granda

Copyright (C) 2015 Kangwen Sun et al. This is an open access article distributed under the Creative Commons Attribution License, which permits unrestricted use, distribution, and reproduction in any medium, provided the original work is properly cited.

The application of single solar array on high-altitude unmanned aircraft will waste energy because of its low conversion efficiency. Furthermore, since its energy utilization is limited, the surface temperature of solar array will rise to $70^{\circ} \mathrm{C}$ due to the waste solar energy, thus reducing the electrical performance of the solar array. In order to reuse the energy converted into heat by solar array, a hybrid power system is presented in this paper. In the hybrid power system, a new electricity-generating method is adopted to spread the photovoltaic cell on the wing surface and arrange photothermal power in the wing box section. Because the temperature on the back of photovoltaic cell is high, it can be used as the high-temperature heat source. The lower wing surface can be a lowtemperature cold source. A high-altitude unmanned aircraft was used to analyze the performances of pure solar-powered aircraft and hybrid powered aircraft. The analysis result showed that the hybrid system could reduce the area of wing by $19 \%$ and that highaltitude unmanned aircraft with a $35 \mathrm{~m}$ or less wingspan could raise the utilization rate of solar energy per unit area after adopting the hybrid power system.

\section{Introduction}

The use of electric power for flight vehicle propulsion is not new [1]. The first one was the hydrogen-filled dirigible France in year 1884 that won a $10 \mathrm{~km}$ race around Villacoublay and Meudon [2]. However, in order to realize "eternal flight," solar energy is the best option due to its characteristic of recycling.

Since the first flight of a solar-powered aircraft (Sunrise I, designed by R. J. Boucher, Astro Flight Inc.) was succeeded on the dry lake at Camp Irwin, California, on November 4, 1974 [3], more and more solar-powered aircraft had been designed and validated (see Figure 1).

The most important solar-powered aircraft are introduced as follows. The first one is the Pathfinder series program developed by AeroVironment Inc. and supported by the US government funding [4-6]. During the implementation of this program, four prototypes were established: Pathfinder, Pathfinder Plus, Centurion, and Helios. The Helios aimed to demonstrate sustained flight at an altitude near $30,480 \mathrm{~m}$ $(100,000 \mathrm{ft})$ and to fly without stop for at least $24 \mathrm{~h}$. Unfortunately, it never reached the second objective as it was destroyed when it fell into the Pacific Ocean on June 26, 2003, due to the too large structure and structural failures [4]. The second one is Zephyr series program developed by QinetiQ in the UK with the UK Ministry of Defense [7, 8]. Zephyr was a lightweight UAV (e.g., the latest Zephyr 7 was only $53 \mathrm{~kg}$ ) designed to fly at the altitude up to $20,000 \mathrm{~m}$ for months at a time. However, its payload was only $2.5 \mathrm{~kg}$ showing the narrow application prospect. At present, a genuinely useful solar-powered aircraft is not available.

Currently, the main technology of photovoltaic cell is to generate electricity from photoelectric characteristics [9], but only the shorter wavelength light is utilized. Taking the silicon-based photovoltaic cells as an example, silicon solar battery only absorbs the light with the shorter wavelength and the light energy is fully converted into heat energy when the wavelength of the light is greater than $1.2 \mu \mathrm{m}$. The heat will not only make the temperature of battery rise to $70^{\circ} \mathrm{C}$ or above in certain circumstance $[10,11]$ but also lead to the sharp decline of cell efficiency.

Therefore, due to the low conversion efficiency and low specific power of photovoltaic cells, the current high-altitude unmanned aircraft design size is large, while the load capacity is limited $[12,13]$. On the other hand, in order to realize 


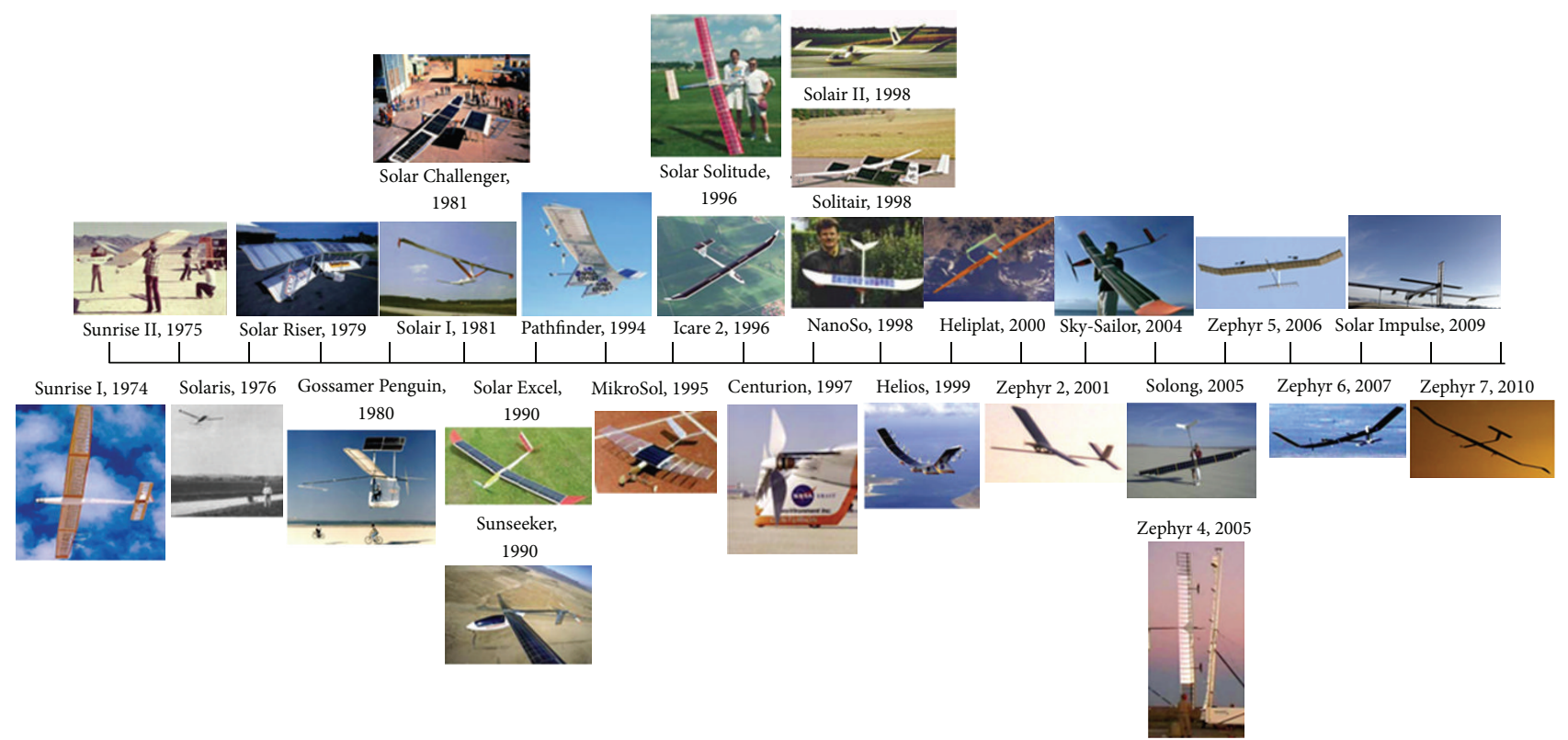

FIGURE 1: The main solar-powered flights around the world.

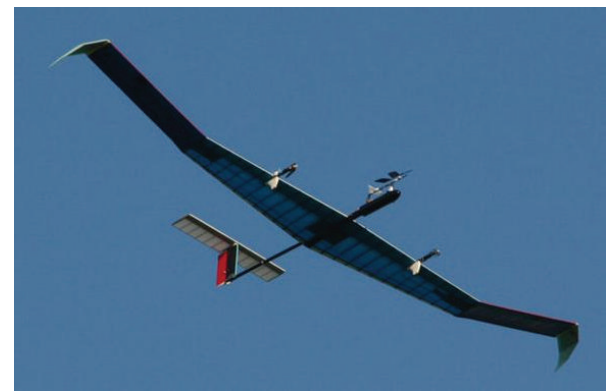

FIGURE 2: The Zephyr 7 of QinetiQ during a flight test.

"eternal flight," we also need to use the fuel cell or lithium battery or both of the combinations [14] to cooperate with the solar cell to achieve the energy recycling.

Zephyr (shown in Figure 2) is categorized as the lightweight solar-powered UAV (unmanned aerial vehicle).

The aircraft is made of carbon-fiber material which can utilize solar energy through the solar array (from UNISOLAR) to drive two propellers and charge the installed lithium sulphur batteries (from Sion Power). Zephyr 7 holds the official aircraft-endurance world record for the UAV. The record has been verified by the FAI (Fédération Aéronautique Internationale) in the duration (14 days and $21 \mathrm{~min}$ in Yuma, 2010) and altitude (the maximum altitude is $24,560 \mathrm{~m}$ ) [8, 15]. Based on Zephyr, a new solar-powered UAV has been constructed at Mälardalen University [16]. In this paper, taking the Zephyr 7 solar-powered UAV as a model, we analyzed the performances of both pure photovoltaic cell and hybrid power used in the solar aircraft.

\section{Traditional Design of Pure Photovoltaic Cell}

The main components of the aircraft include fuselage, motor, solar array, storage battery, and straight wing with the high lift
TABLE 1: The wing parameters of Zephyr 7.

\begin{tabular}{lc}
\hline Parameter & Value \\
\hline Wingspan & $22.5 \mathrm{~m}$ \\
Chord & $1.185 \mathrm{~m}$ \\
Area & $32.6 \mathrm{~m}^{2}$ \\
Wing weight & $28 \mathrm{~kg}$ \\
Aerofoil & EPPLER 395 \\
\hline
\end{tabular}

coefficient. Relevant data of the wing are provided as shown in Table 1 [17].

Because the wing is a straight wing manufactured with carbon-fiber composite materials, the structural weight of wing has an approximately linear correlation with wingspan. Therefore, the structural weight of wing per wingspan is about $G_{W l}=0.6 \mathrm{~kg} / \mathrm{m}$.

The Sun Power CSS125-125, which was one of the most efficient solar panels commercially available nowadays, was selected to constitute the solar panel. The solar panel with 96 photovoltaic cells has the conversion efficiency of $19.6 \%$. The related parameters of the solar panel are described as follows: max power $320 \mathrm{~W}$, temperature range between $-40^{\circ} \mathrm{C}$ and $85^{\circ} \mathrm{C}$, the power per wingspan $\left(P_{S l}=17.48 \mathrm{~W} / \mathrm{m}\right)$, and the weight of photovoltaic system per wingspan $\left(G_{S l}=1 \mathrm{~kg} / \mathrm{m}\right)$.

Welgard Motor C1823-20 is the most efficient power system with the minimal requirement of motor power input of $33.2 \mathrm{~W}$ and the thrust of $192 \mathrm{~g}$. The engine power has a linear relationship with thrust. The formula is $T_{m}=\beta P_{m}$, where $T_{m}$ is the thrust of engine; $P_{m}$ is power of engine; $\beta$ is the scaling factor.

Important data of the weights of other components are described as follows: storage battery (including charger) $\left(G_{B}=2 \mathrm{~kg}\right)$, motor including propeller $\left(G_{M}=1.86 \mathrm{~kg}\right)$, 
and other systems $\left(G_{O}=3.07 \mathrm{~kg}\right)$. The total weight of solarpowered aircraft with only photovoltaic cells is

$$
G_{S}=l G_{W l}+l G_{S l}+G_{B}+G_{M}+G_{O}=1.6 l+5.93 .
$$

The specific power-to-weight ratio for the aircraft is

$$
\lambda_{S}=\frac{P_{S l}}{G_{S}}=\frac{17.48 l}{(1.6 l+5.93)} .
$$

The lift can be calculated according to (2) [18]:

$$
L=\frac{1}{2} \rho V^{2} S_{\text {ref }} C_{L},
$$

where $L$ is lift; $S_{\text {ref }}$ is the area of wing; $C_{L}$ is the lift coefficient. The equation of drag is expressed as [18]

$$
D=\frac{1}{2} \rho V^{2} S_{\text {ref }} C_{D}
$$

where $D$ is the drag; $S_{\text {ref }}$ is the area of wing; $C_{D}$ is the drag coefficient. In addition, the lift $L$ is equal to the aircraft weight $W$, and the thrust $T$ is equal to the aircraft drag in straight and level flight.

\section{A Photovoltaic and Thermal Module}

In order to improve the solar-powered aircraft flight capability, many scholars have proposed a variety of ideas. For example, Brandt and Gilliam proposed storing energy by gravitational potential and believed that the plane could use plenty of solar energy to climb up in the day and be an unpowered glider at night to reduce battery mass [19]. However, Brandt only gave the initial idea. Sachs and Costa studied the solar-powered aircraft flight trajectory with minimum energy storage and found that when climbing in the day and gliding at night, theoretically, solar-powered aircraft could realize the flight in day and night without any storage battery. However, the maximum climbing height in the day is more than $20 \mathrm{~km}$ and the minimum gliding height at night is only about $1 \mathrm{~km}$. The difference between the maximum climbing height and the minimum gliding height does not meet the design requirements because of large flight altitude span [20]. Gao et al. from National University of Defense Technology studied the high-altitude long-endurance flight based on energy extraction from wind shear and put forward the idea of dynamics simulation. However, the idea requires the infrastructure for monitoring wind field [7, 21].

In addition, solar radiation in the normal direction of the wing plane can be increased by adjusting the aircraft's flight attitude. In order to maximize remaining energy, Klesh and Kabamba established the analysis models of flight dynamics, solar radiation intensity, and energy consumption on flight attitude and studied the relationship between the solarpowered aircraft flight trajectory of hovering at a given height and remaining energy [22]. The analysis results showed that remaining energy obtained by optimized hovering trajectory was greater than the horizontal straight flight. Spangelo et al. expanded the flight space further to study the relationship

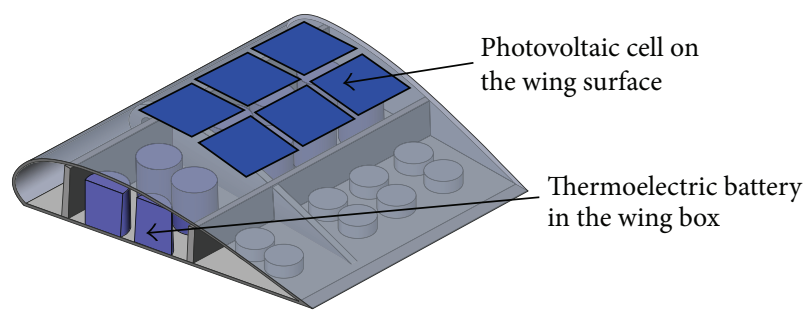

FIGURE 3: Schematic drawing of hybrid energy (photothermal cell) wing structure.
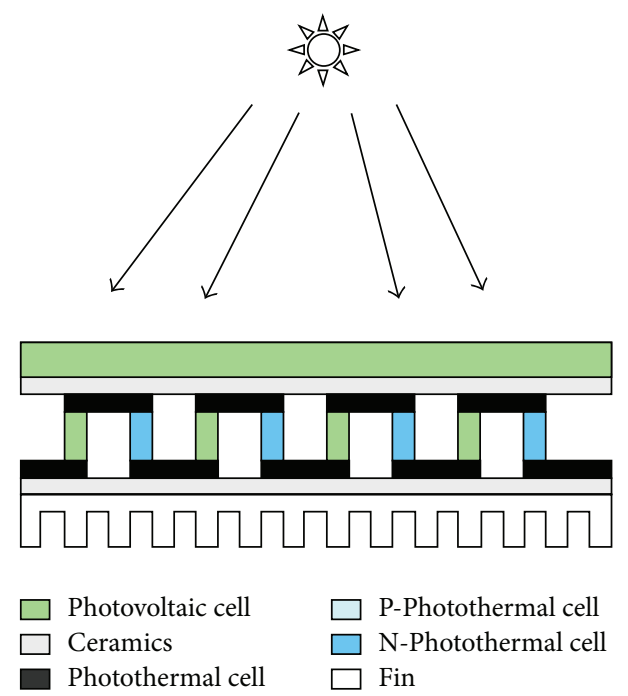

FIgURE 4: The structure of hybrid energy (photothermal cell).

between flight trajectory and the remaining energy in threedimensional cylindrical space, presented the design method for flight trajectory optimization, and finally obtained the same results to Spangelo et al's [23]. However, in these methods, the flying platform should meet the established mission profile to some extent, thus limiting the wide application of solar aircraft.

These studies could not enhance the actual power output capability of flying platform essentially. Therefore, the longendurance flight capacity of solar-powered aircraft cannot be effectively utilized according to the mission requirements. Based on the structural characteristics of the aircraft, the analysis of solar-powered aircraft flight environment, and the temperature change on the surface of the photovoltaic cell, in the paper, we innovatively designed a photovoltaicthermoelectric (photothermal cell) hybrid power system with the wing structure, which could improve the flight performance of solar-powered aircraft by increasing the transmission capacity of the energy system. In the system, the photovoltaic cells are spread on the wing surface and thermoelectric batteries are arranged in the wing box section because the temperature on the back of photovoltaic battery is high. The back of photovoltaic cells can be used as hightemperature heat source and the lower wing surface can be a low-temperature cold source, as shown in Figures 3 and 4. This design can reuse the solar energy converted into heat. 


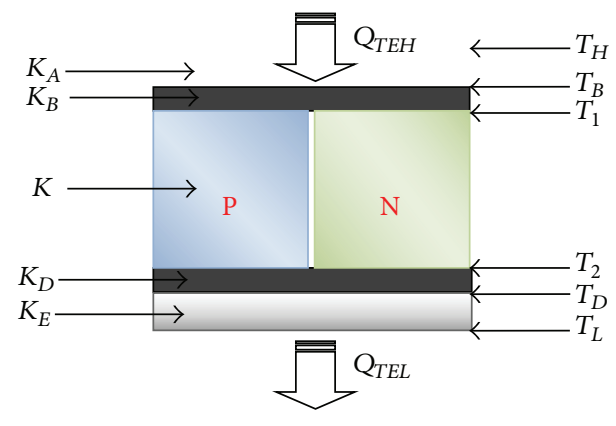

FIGURE 5: Thermoelectric battery structural representation.

Therefore, the efficiency of solar energy per area is increased. Moreover, the ambient temperature is also decreased.

\section{Impact of Thermal Conductivity on Thermoelectric Battery}

In the schematic diagram of thermoelectric battery structure (Figure 5), $T_{H}, T_{L}, T_{1}, T_{2}, T_{B}$, and $T_{D}$, respectively, represent the temperatures of heat source, cold source, heat plate, cold plate, the contact layer of hot side, and the contact layer of cold side. The unit is $\mathrm{K} . K_{A}, K_{E}, K_{B}$, and $K_{D}$, respectively, represent the thermal conductivities of heat plate, cold plate, the contact layer of hot side, and the contact layer of cold side. The unit is $\mathrm{W} / \mathrm{K}$.

We made the following four assumptions on the model. Firstly, air convection and radiation between the thermoelectric cold side and the hot side and air convection and radiation between $\mathrm{P}$ type and $\mathrm{N}$ type semiconductor can be negligible. Secondly, heat exchange does not occur between the environment and other components (heat plate, cold plate, $\mathrm{P}$ type, and $\mathrm{N}$ type semiconductor). Thirdly, heat conduction occurs only along the length direction of the electric arm. Fourthly, the heat conduction coefficient does not vary with the arm length.

Supposing that the heat of the generator absorbed from the contact layer of hot side per unit time is $Q_{T E H}$ and that the heat released from cold side is $Q_{T E L}$, when $K_{H}=K_{A} K_{B} /\left(K_{A}+\right.$ $\left.K_{B}\right)$ and $K_{L}=K_{D} K_{E} /\left(K_{D}+K_{E}\right)$, the following equation can be obtained:

$$
\begin{aligned}
Q_{T E H} & =K_{H}\left(T_{H}-T_{1}\right), \\
Q_{T E L} & =K_{L}\left(T_{2}-T_{L}\right) .
\end{aligned}
$$

Supposing that the heat of the flow generator device absorbed from the heat plate per unit time is $Q_{1}$ and that the heat released from cold side is $Q_{2}$, the heat generated by Peltier effect can be expressed as

$$
\begin{aligned}
& Q_{1}=\alpha I T_{1}, \\
& Q_{2}=\alpha I T_{2},
\end{aligned}
$$

where $\alpha$ is Seebeck coefficient of thermocouple usually expressed in $(\mathrm{V} / \mathrm{K}) ; I$ is the current generated inside the thermoelectric generator.

When the generator works, according to the principle of heat conduction, conduction heat $Q_{k}$ caused by the temperature difference between both sides of the semiconductor component can be expressed as

$$
Q_{k}=K\left(T_{1}-T_{2}\right)
$$

where $K$, the thermal conductivity of components, can be expressed as

$$
K=k_{p} \frac{A_{p}}{l_{p}}+k_{N} \frac{A_{N}}{l_{N}},
$$

where $l_{p}, k_{p}$, and $A_{p}$ and $l_{N}, k_{N}$, and $A_{N}$ are the length, conductivity, and cross-sectional area of P-type and N-type legs, respectively.

Joule heat flux $Q_{J}$, generated by one pair of semiconductor legs when the current goes through the generator, is

$$
Q_{J}=r I^{2}
$$

Let $f=K_{H}\left(K_{L}+2 K\right) / 2\left(K_{H} K_{L}+K_{H} K+K K_{L}\right)$; thus the heat flow Joule heat $Q_{J}$ transferring to the hot side and cold side is $f Q_{J}$ and $(1-f) Q_{J}$, respectively. Therefore, the heat $Q_{T E H}$ of the generator absorbed from the contact layer of hot side can be expressed as

$$
Q_{T E H}=Q_{1}-f Q_{J}+Q_{K}
$$

At the same time, the heat $Q_{T E L}$ released from cold side is

$$
Q_{T E L}=Q_{2}-(1-f) Q_{J}+Q_{K}
$$

Therefore, the output power of the thermoelectric battery is

$$
P_{T E}=Q_{T E H}-Q_{T E L}
$$

When $\beta=K_{A} K_{B}\left(K_{D}+K_{E}\right), \gamma=K_{D} K_{E}\left(K_{A}+K_{B}\right), \delta=$ $K_{D} K_{E} K_{A} K_{B}$, and $\xi=K(\beta+\gamma)+\delta$, (12) can be converted into

$$
P_{T E}=\frac{\alpha \gamma[(1-f) \gamma-f \beta] I^{3}+\left[\alpha^{2}\left(T_{H} \beta+T_{L} \gamma\right)+\gamma \xi\right] I^{2}-\alpha \delta\left(T_{H}-T_{L}\right) I}{\left(K_{A}+K_{B}\right)\left(K_{D}+K_{E}\right) \alpha^{2} I^{2}+\alpha(\beta-\gamma) I-\xi} .
$$


The power generation efficiency of the thermoelectric battery can be expressed as $\eta_{T E}=P_{T E} / Q_{T E H}$. Then we get

$$
\eta_{T E}=\frac{\alpha \gamma[(1-f) \gamma-f \beta] I^{3}+\left[\alpha^{2}\left(T_{H} \beta+T_{L} \gamma\right)+\gamma \xi\right] I^{2}-\alpha \delta\left(T_{H}-T_{L}\right) I}{\left[\left(T_{H} \alpha^{2}+K r\right) \beta+f r \delta\right] \alpha^{2} I^{2}-f r \alpha \beta I^{3}+\alpha \delta I-K \delta\left(T_{H}-T_{L}\right)} .
$$

The effects of thermal conduction on the output power and efficiency of the hybrid system designed in this paper are described as follows. The cold side has an important influence on the efficiency. Moreover, the heat dissipation efficiencies of both P-N junction and the cold side have a decisive role in heat dissipation of the system. Therefore, in the paper, we analyzed the influences of the thermal conductivity of cold side and P-N junction on the output power and efficiency.

Supposing that the back of photovoltaic cell is the heat plate, because the back temperature of photovoltaic cells can reach $70^{\circ} \mathrm{C}$, the temperature of heat source is assumed to be $100^{\circ} \mathrm{C}$. Moreover, the temperature of the cold plate is the same to ambient temperature. Let $r$ be $5 \times 10^{-4} \Omega$. The contact layer of the hot side is made of ceramic material of the high thermal conductivity. Both $K_{A}$ and $K_{B}$ are $1 \mathrm{~W} / \mathrm{K}$. Then, the curves of the variations of output power and efficiency with the thermal conductivities of cold side $\left(K_{D}\right)$ and P-N junction $(K)$ can be obtained, as shown in Figures 6-9.

From Figures 6 to 9, the following conclusions can be obtained.

When the thermal conductivities of components vary from $0.01 \mathrm{~W} / \mathrm{K}$ to $0.02 \mathrm{~W} / \mathrm{K}$ and $0.03 \mathrm{~W} / \mathrm{K}$, the maximum output power is reduced from $0.0159 \mathrm{~W}$ to $0.0116 \mathrm{~W}$ and $0.0089 \mathrm{~W}$. The reduction ratios are $37.1 \%$ and $30.3 \%$, respectively. The efficiency decreases from $2.7 \%$ to $1.15 \%$ and $0.67 \%$. The reduction ratios are $13.4 \%$ and $71.5 \%$, respectively. The output power and efficiency of thermoelectric generator decrease with the increase of thermal conductivity of components and the decreasing rate is growing. The change can be interpreted as follows. When thermal conductivities of components are decreased, conduction heat going through the components is decreased, thus greatly increasing the temperature difference between both sides of the generator. In this way, both the output power and efficiency are increased. From the magnitude of the trend, we can see that the power and efficiency of generator are very sensitive to thermal conductivities of components. Therefore, in the selection of the materials for the hybrid system, the priority should be given to the material properties of the generator.

When the thermal conductivity of the contact layer of cold side varies from $0.075 \mathrm{~W} / \mathrm{K}$ to $0.1 \mathrm{~W} / \mathrm{K}$, the maximum output power is increased from $0.0122 \mathrm{~W}$ to $0.0137 \mathrm{~W}$ and the increase ratio is $12.3 \%$. When it varies from $0.1 \mathrm{~W} / \mathrm{K}$ to $0.125 \mathrm{~W} / \mathrm{K}$, the maximum output power is increased from $0.0137 \mathrm{~W}$ to $0.0146 \mathrm{~W}$ and the increase ratio is $6.6 \%$. The output power and efficiency of semiconductor components increase with the increase in the thermal conductivity of the contact layer of cold side, but the increasing rate is becoming smaller. The change can be interpreted as follows. When the temperatures of heat source and cold source are constant, the higher heat conductivity coefficient of cold side indicates the better heat conduction. In this way, the flow of the heat across the components is increased and the thermoelectric energy conversion of the battery and its electromotive force are improved. Finally, the output power and efficiency are increased. With the further increase in the thermal conductivity of the cold side, the heat conduction of components as well as the total heat flow is limited. This is why the increasing rate becomes smaller. For the solarpowered aircraft, it is impossible to obtain a high heat transfer coefficient through the complex cold side. Moreover, the complex cold side does not bring out a huge increase in the efficiency.

More accurate analysis, that is, statistical analysis, can be achieved by the following two methods: the Design of Experiments (DOE) [24] and Response Surface Methodology (RSM) [25].

\section{The Improved Design of the Hybrid Power System}

Because the size of PN junction has an important influence on the efficiency of thermoelectric battery, it is necessary to study the proper number of thermoelectric batteries in the box and find the optimal length of PN junction coming firstly. Considering the specific characteristics of solar-powered aircraft [26], in this paper, we used the power-to-weight ratio as the best indicator to measure the quality of the design of photothermal cell.

Photothermal cell power generation system involves the heat collecting process, heat-electricity conversion process, and cooling process. The heat collection is realized by photovoltaic cells. Thermoelectric generator is composed of the hot deflector, the PN junction, the cold deflector, and heat dissipation through convection between the lower wing surface and air [27]. According to Newton's law of thermodynamics, the temperature difference between twoarm ends of thermopile leads to thermal current flows. The heat obtained by the couple arm from the heat end is the sum of Pult heat, Joule heat, and conduction heat [28]. The formulas are expressed as follows:

$$
\begin{aligned}
Q_{h} & =n \alpha I T_{1}-\frac{I^{2} R}{2}+K\left(T_{1}-T_{2}\right), \\
Q_{c} & =n \alpha I T_{2}+\frac{I^{2} R}{2}+K\left(T_{1}-T_{2}\right), \\
K & =n\left(\frac{k_{p} A_{p}}{l_{p}}+\frac{k_{n} A_{n}}{l_{n}}\right), \\
R & =n\left(\frac{\rho_{p} l_{p}}{A_{p}}+\frac{\rho_{n} l_{n}}{A_{n}}\right),
\end{aligned}
$$




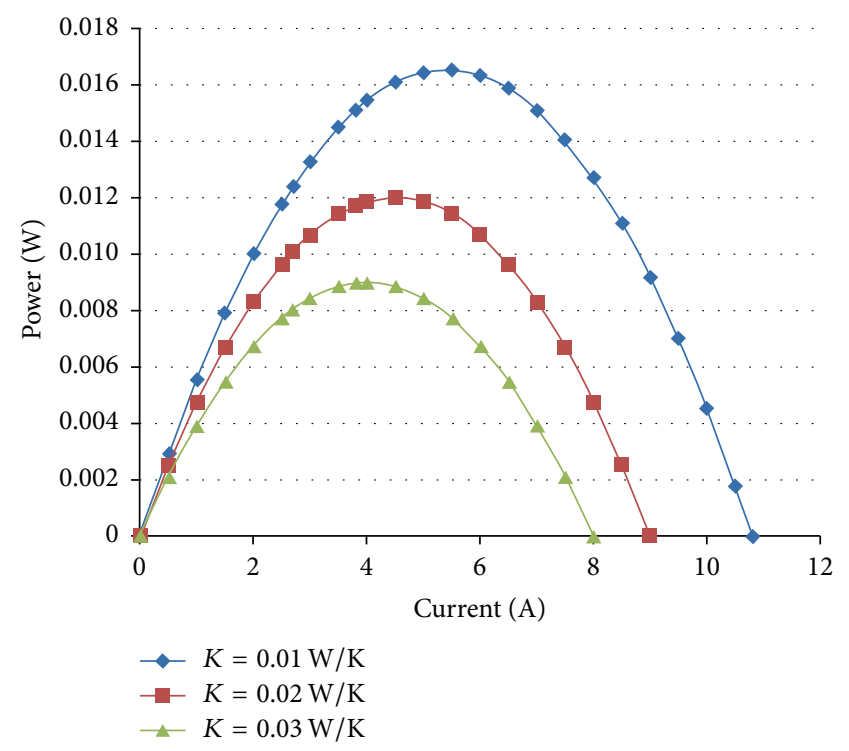

FIgURE 6: The curves of output power variation with the current under different $K$.

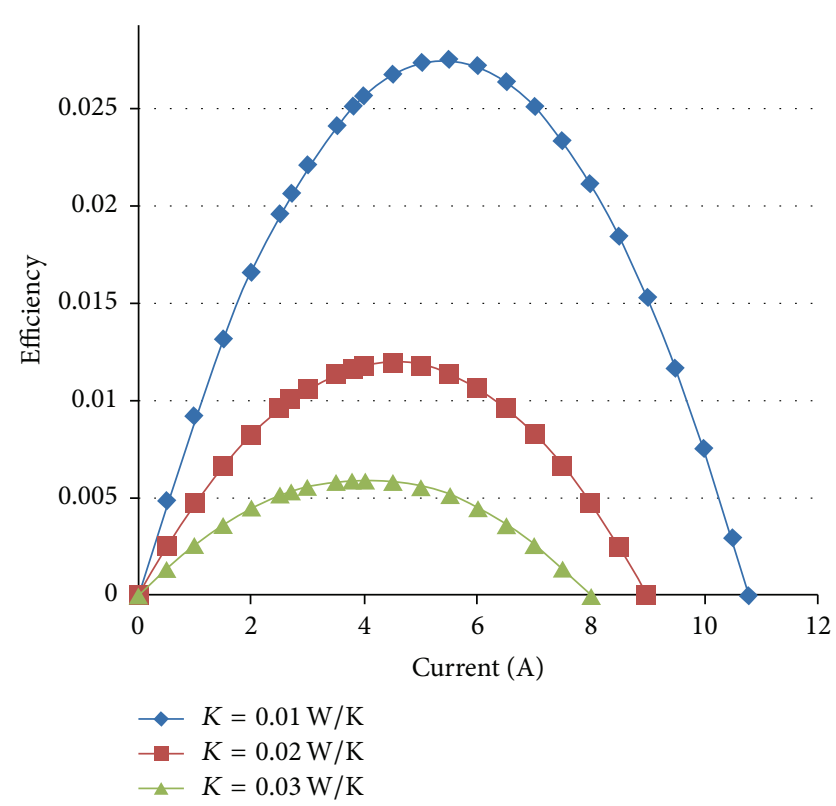

FIGURE 7: The curves of efficiency variation with the current under different $K$.

where $Q_{h}$ is heat absorbed by the generator from heat source; $Q_{c}$ is heat absorbed from cold side; $I$ is the loop current; $R_{L}$ is load resistance; $R$ is couple arm resistance; $\alpha$ is the Seebeck coefficient; $K$ is the thermal conductivity of the device; $k_{p}, k_{n}, l_{p}, l_{n}, \rho_{p}$, and $\rho_{n}$ are, respectively, the temperatures of heat source and cold side, thermal conductivity, length, and the cross-sectional area, and electrical resistivity of the $\mathrm{P}$ type and $\mathrm{N}$ type semiconductor; $n$ is the number of generators.

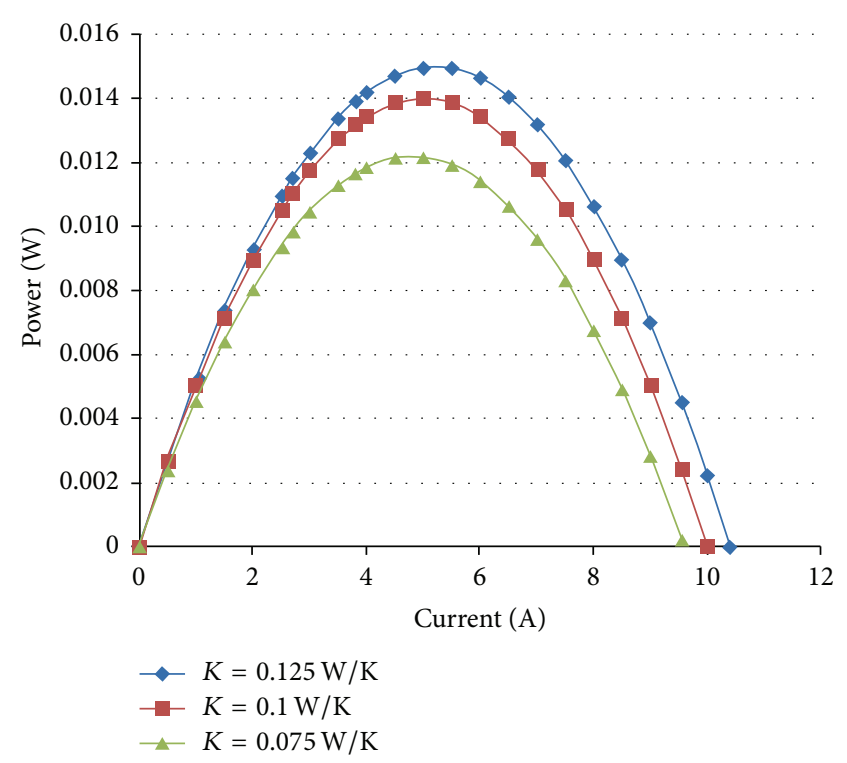

FIGURE 8: The curves of output power variation with the current under different $K_{D}$.

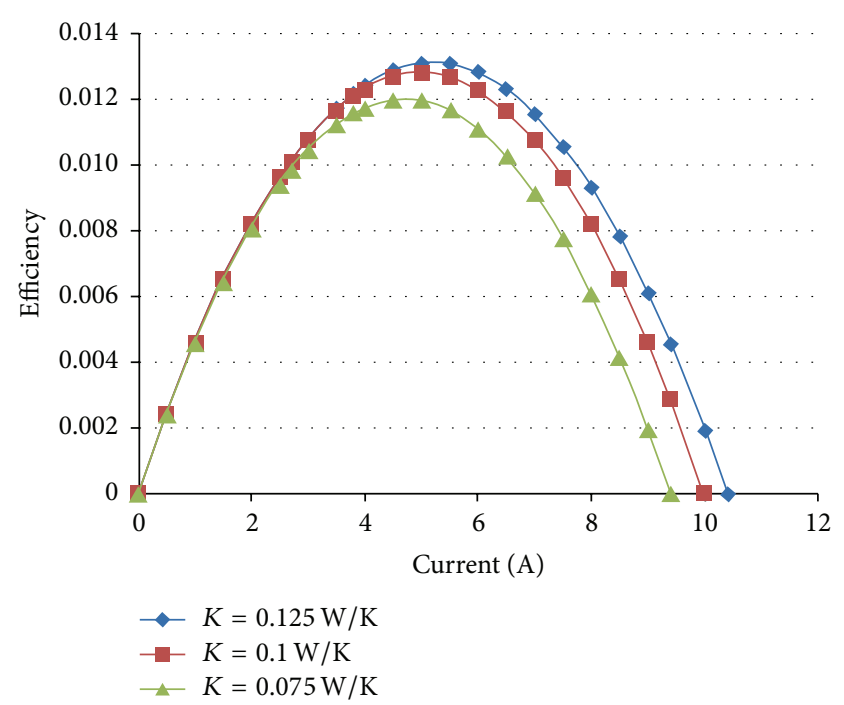

FIGURE 9: The curves of efficiency variation with the current under different $K_{D}$.

Therefore, the expression of electromotive force $\varepsilon$, electrical current $I$, and the output power $P$ can be given as follows:

$$
\begin{aligned}
& \varepsilon=n \alpha\left(T_{1}-T_{2}\right), \\
& I=\frac{\varepsilon}{\left(R+R_{L}\right)}, \\
& P=I^{2} R_{L} .
\end{aligned}
$$

The basic expression of the power-to-weight ratio is

$$
\lambda=\frac{P}{\rho\left(A_{p} l_{p}+A_{n} l_{n}\right)} .
$$




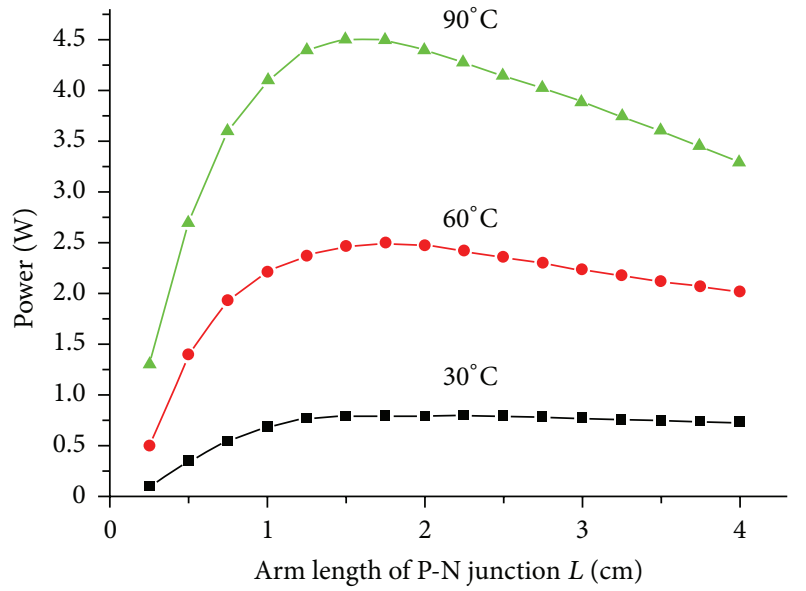

Figure 10: The curve of power versus arm length.

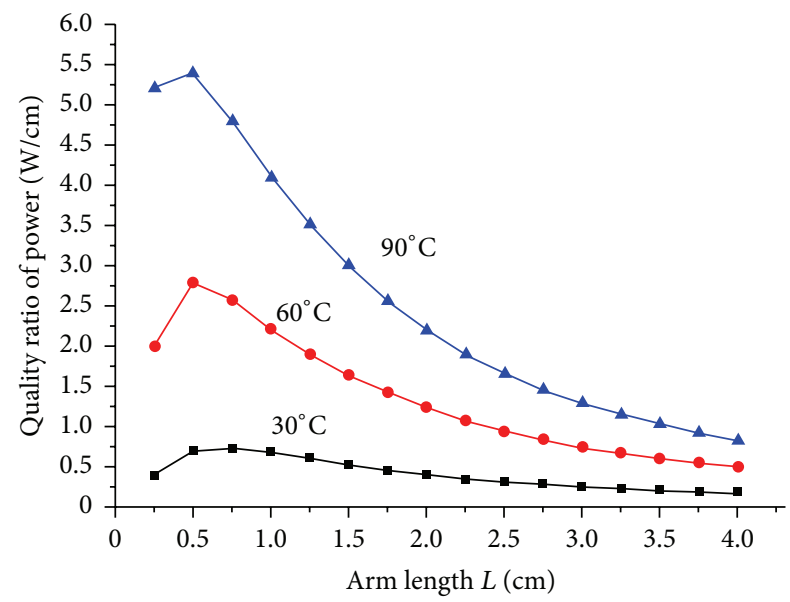

FIGURE 11: The curve of power-to-weight ratio versus arm length.

With above formulas, the power-to-weight ratio can be given as

$\lambda$

$$
=\frac{K I\left\{n a K\left(T_{1}+T_{2}\right)-n K\left(R+R_{L}\right) I-n^{2} I\left[\alpha^{2}\left(T_{1}+T_{2}\right)+2 K R\right]\right\}}{\left(K^{2}-n^{2} \alpha^{2} I^{2}+2 n^{2} K^{2}\right)\left(A_{p} l_{p}+A_{n} l_{n}\right)} .
$$

P-N junction area does not affect the output power per unit area of the wing [29]. Therefore, we studied the influence of single $\mathrm{PN}$ junction (P-end has the same length with $\mathrm{N}$ end). The cross-sectional area is $1 \mathrm{~cm} \times 1 \mathrm{~cm}$. The parameters are provided as follows. $\mathrm{P}$ junction has the same parameters with $\mathrm{N}$ junction: $A=3 \mathrm{~cm}^{2}, \alpha=4.83 \times 10^{-4} \mathrm{~V} / \mathrm{K}, R_{L}$ $=0.003 \Omega$, and $K=25 \mathrm{~W} /(\mathrm{m} \cdot \mathrm{K})$ [30]. The environment temperature is considered as the temperature of the cold side. Figure 10 shows the variation of power output with temperature under the influences of PN junction arm length. Figure 11 shows the variation of power-to-weight ratio with temperature under the influence of length of P-N junction arm.

The result shows that when the arm length of $\mathrm{P}-\mathrm{N}$ junction is $1.75 \mathrm{~cm}$, the output power reaches the peak. However, when the ratio of power-to-weight reaches the peak, the arm length of P-N junction should be $0.5 \mathrm{~cm}$. Therefore, the size of PN junction should be set as $1 \mathrm{~cm} \times 1 \mathrm{~cm} \times 0.5 \mathrm{~cm}$ in the design of this paper. The thickness of wing is about $43.5 \mathrm{~mm}$. Considering the thickness of the fin and the heattransferring ceramic, we set $n$ to be 5 , indicating that 5 layers of thermoelectric batteries are arranged in the wing box. At room temperature, the rated power is set to be $7.6 \mathrm{~W} / \mathrm{m}^{2}$; the thermoelectric power per wingspan is $P_{P l}=9 \mathrm{~W} / \mathrm{m}$. The weight of the thermoelectric system per wingspan is $G_{P l}=0.9 \mathrm{~kg} / \mathrm{m}$. Therefore, the gross weight of the hybrid solar system-powered aircraft is expressed as

$$
\begin{aligned}
G_{P} & =l G_{W l}+l\left(G_{S l}+G_{P l}\right)+G_{B}+G_{M}+G_{O} \\
& =2.5 l+5.93 .
\end{aligned}
$$

In order to compare the performances of those two aircraft, we take the same value for $C_{L}$ and $C_{D}$. Therefore, in the design of pure PV, while the plane is under the cruise state, we get the following equations:

$$
\begin{aligned}
& \frac{1}{2} \rho V^{2} S_{\mathrm{ref}} C_{D}=G_{S}=1.6 l_{1}+5.93, \\
& \frac{1}{2} \rho V^{2} S_{\mathrm{ref}} C_{L}=T=\beta P_{S l} l_{1} .
\end{aligned}
$$

In the design of the hybrid system, while the plane is under cruise state, we get the following equations:

$$
\begin{aligned}
& \frac{1}{2} \rho V^{2} S_{\mathrm{ref}} C_{D}=G_{P}=2.5 l_{2}+5.93 \\
& \frac{1}{2} \rho V^{2} S_{\mathrm{ref}} C_{L}=T=\beta\left(P_{S l}+P_{P l}\right) l_{2} .
\end{aligned}
$$

The next equation can be obtained from the above four equations:

$$
\frac{17.48 l_{1}}{26.5 l_{2}}=\frac{\left(1.6 l_{1}+5.93\right)}{\left(2.5 l_{2}+5.93\right)},
$$

where $l_{1}$ is $22.5 \mathrm{~m}$; then $l_{2}$ can be figured out as $18.2 \mathrm{~m}$ according to (22). The result shows that the hybrid system can reduce the wingspan by $4.3 \mathrm{~m}(19 \%)$ under the condition of Zephyr 7. Therefore, the wing area can be reduced by $19 \%$. follows:

The power-to-weight ratio for the aircraft can be given as

$$
\lambda=\frac{\left(P_{P l}+P_{S l}\right)}{G_{P}}=\frac{26.5 l}{2.5 l+5.93} .
$$

After comparing the power-to-weight ratio of hybrid power system with that of photovoltaic system under different wingspan states, we got the following equation:

$$
a=\frac{\lambda_{P}}{\lambda_{S}}=\frac{1.156\left(1.6 l_{1}+5.93\right)}{\left(2.5 l_{2}+5.93\right)} .
$$

Figure 12 can be obtained with (24). As shown in Figure 12, when wingspan is less than $35 \mathrm{~m}$, the power-toweight ratio of hybrid solar system-powered aircraft is higher 


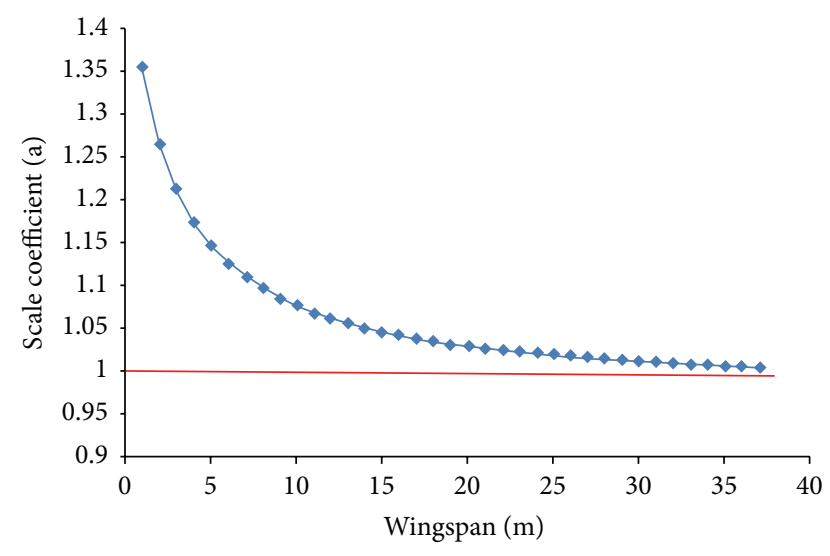

FIGURE 12: Power-to-weight ratios of two aircraft.

than that of photovoltaic solar system-powered aircraft. An opposite result will be obtained when the wingspan is higher than $35 \mathrm{~m}$.

Based on the photovoltaic system, the addition of the thermoelectric system can increase the output power per unit area of photovoltaic cell. When the output power meets the requirement of engine power, the area and weight of wing can be reduced. Therefore, the aircraft requires a lower lift and reduces the requirement of engine power. However, at the same time, the weight per unit area of solar system is increased. Therefore, the weight per unit area of the wing is also increased. The overall lift is decreased because the area of wing is reduced. Due to the above influences, the aircraft requires the higher engine power in return. The solarpowered aircraft with hybrid power system has the excellent performance when its wingspan is less than $35 \mathrm{~m}$.

\section{Conclusions}

Combined with the wing configuration, we presented a hybrid energy design method with the higher efficiency. Taking Zephyr 7 as an example, we analyzed the weight and power of two aircraft designs which, respectively, used photovoltaic system and hybrid system. Comparative analysis shows that the hybrid system can effectively reduce the wing area by $19 \%$.

Moreover, because power-to-weight ratio is an important performance indicator, we compared the two designs in this paper. Aircraft can adopt a photovoltaic-thermoelectric hybrid power system when the wingspan is less than $35 \mathrm{~m}$. To some extent, the hybrid system can increase the utilization of solar energy and reduce the weight of the whole structure.

\section{Conflict of Interests}

The authors declare that they do not have any commercial or associative interests that represent a conflict of interests in connection with the work submitted.

\section{Acknowledgments}

This work was supported by the National Natural Science Foundation of China under Grant no. 51307004 and the Fundamental Research Funds for the Central Universities (YWF -15-GJSYS-025).

\section{References}

[1] M. Hoffborn, A historical survey of solar powered airplanes and evaluation of it's potential market [Bachelor thesis], Malardalen University, Västerås, Sweden, 2009.

[2] A. Noth, "History of solar flight," in Proceedings of the 26th Congress of International Council of the Aeronautical Sciences (ICAS '08), Anchorage, Alaska, USA, September 2008.

[3] A. Noth, Design of solar powered airplanes for continuous flight [Ph.D. dissertation], Ecole Polytechnique Fédérale de Lausanne, ETH Zürich, Zürich, Switzerland, 2008.

[4] T. E. Noll, J. M. Brown, M. E. Perez-Davis, S. D. Ishmael, and G. C. Tiffany, Investigation of the Helios Prototype Aircraft Mishap: Volume I Mishap Report, NASA Langley Research Center, Hampton, Va, USA, 2004.

[5] N. J. Colella and G. S. Wenneker, Pathfinder and the Development of Solar Rechargeable Aircraft, 1994, https://str.llnl.gov/ etr/pdfs/07_94.1.pdf.

[6] P. G. Carey, R. C. Aceves, N. J. Colella, K. A. Williams, R. A. Sinton, and G. S. Glenn, "A solar module fabrication process for hale solar electric UAVS," in Proceedings of the 24th IEEE Photovoltaic Specialists Conference, Waikoloa, Hawaii, USA, December 1994.

[7] X.-Z. Gao, Z.-X. Hou, Z. Guo, R.-F. Fan, and X.-Q. Chen, "The equivalence of gravitational potential and rechargeable battery for high-altitude long-endurance solar-powered aircraft on energy storage," Energy Conversion and Management, vol. 76, pp. 986-995, 2013.

[8] X. F. Zhu, Z. Guo, and Z. X. Hou, "Solar-powered airplanes: a historical perspective and future challenges," Progress in Aerospace Sciences, vol. 71, pp. 36-53, 2014.

[9] A. E. Shahat, "PV module optimum operation modeling," Journal of Power Technologies, vol. 94, no. 1, pp. 50-66, 2014.

[10] K. Khouzam, K. K. Chen, and Y. N. Poo, "Simulation and realtime modelling of space photovoltaic systems," in Proceedings of the 24th IEEE Photovoltaic Specialists Conference. Part 2 (of 2), pp. 38-41, 1994.

[11] K. Sun, M. Zhu, and Q. Liu, "Membrane material-based rigid solar array design and thermal simulation for stratospheric airships," Advances in Materials Science and Engineering, vol. 2014, Article ID 192707, 7 pages, 2014.

[12] E. Koutroulis, K. Kalaitzakis, and N. C. Voulgaris, "Development of a microcontroller-based, photovoltaic maximum power point tracking control system," IEEE Transactions on Power Electronics, vol. 16, no. 1, pp. 46-54, 2001.

[13] C. L. Nickol, M. D. Guynn, L. L. Kohout, and T. A. Ozoroski, High Altitude Long Endurance Air Vehicle Analysis of Alternatives and Technology Requirements Development., American Institute of Aeronautics and Astronautics, 2007.

[14] M. Dudek, P. Tomczyk, P. Wygonik, M. Korkosz, P. Bogusz, and B. Lis, "Hybrid fuel cell-battery system as a main power unit for small unmanned aerial vehicles (UAV)," International Journal of Electrochemical Science, vol. 8, pp. 8442-8463, 2013. 
[15] A. Rapinett, Zephyr. A high altitude long endurance unmanned air vehicle [M.S. thesis], University of Surrey, 2009, http:// personal.ph.surrey.ac.uk/ phslpr/mphys-dissertations/2009/ Rapinett-MPhys09.pdf.

[16] A. Sultan, Solaris project: the design of a solar powered UAV [Bachelor thesis], School of Innovation, Design and Engineering, Mälardalen University, Västerås, Sweden, 2011.

[17] C. Y. Yin, P. Y. Gao, J. Guo, Z. Guo, and Z. X. Hou, "Mechanical performance analysis on wing's of Zephyr7 UAV," Structure \& Environment Engineering, vol. 39, no. 3, pp. 19-25, 2012.

[18] A. Noth, R. Siegwart, and W. Engel, "Design of solar powered airplanes for continuous flight," in Aircraft and Spacecraft Systems: Design, Modeling and Control, ETHZ Lecture, 2007.

[19] S. A. Brandt and F. T. Gilliam, "Design analysis methodology for solar-powered aircraft," Journal of Aircraft, vol. 32, no. 4, pp. 703-709, 1995.

[20] G. Sachs and O. Costa, "Optimization of dynamic soaring at ridges," in Proceedings of the AIAA Atmospheric Flight Mechanics Conference and Exhibit, Austin, Tex, USA, 2003.

[21] X.-Z. Gao, Z.-X. Hou, Z. Guo, P. Wang, and J.-T. Zhang, "Research on characteristics of gravitational gliding for highaltitude solar-powered unmanned aerial vehicles," Proceedings of the Institution of Mechanical Engineers, Part G: Journal of Aerospace Engineering, vol. 227, no. 12, pp. 1911-1923, 2013.

[22] A. T. Klesh and P. T. Kabamba, "Energy-optimal path planning for solar-powered aircraft in level flight," in Proceedings of the AIAA Guidance, Navigation and Control Conference and Exhibit, Hilton Head, SC, USA, August 2007.

[23] S. C. Spangelo, E. G. Gilberty, A. T. Klesh, P. T. Kabamba, and A. R. Girard, "Periodic energy-optimal path planning for solar-powered aircraft," in Proceedings of the AIAA Guidance, Navigation, and Control Conference, Chicago, Ill, USA, August 2009.

[24] F. Sánchez Lasheras, J. A. Vilán Vilán, P. J. García Nieto, and J. J. del Coz Díaz, "The use of design of experiments to improve a neural network model in order to predict the thickness of the chromium layer in a hard chromium plating process," Mathematical and Computer Modelling, vol. 52, no. 7-8, pp. 1169-1176, 2010.

[25] J. J. del Coz Diaz, P. J. Garcia-Nieto, F. P. Alvarez-Rabanall, M. Alonso-Martínez, J. Dominguez-Hernandez, and J. M. PerezBella, "The use of response surface methodology to improve the thermal transmittance of lightweight concrete hollow bricks by FEM," Construction and Building Materials, vol. 52, pp. 331-344, 2014.

[26] Y. Vorobiev, J. González-Hernández, P. Vorobiev, and L. Bulat, "Thermal-photovoltaic solar hybrid system for efficient solar energy conversion," Solar Energy, vol. 80, no. 2, pp. 170-176, 2006.

[27] T. Zhang, Z. M. Zhou, X. Z. Huang, G. W. Liang, and B. $\mathrm{Xu}$, "Thermal electric coupling analysis of matched load of semiconductor thermoelectric generator," Chinese Journal of Power Sources, vol. 10, pp. 12-13, 2010.

[28] G. Nakamoto, T. Souma, M. Yamaba, and M. Kurisu, “Thermoelectric properties of $\left(\mathrm{Zn}_{1-x} \mathrm{Cd}_{x}\right)_{4} \mathrm{Sb}_{3}$ below room temperature," Journal of Alloys and Compounds, vol. 377, no. 1-2, pp. 59-65, 2004.

[29] J. C. Chen, B. H. Lin, H. J. Wang, and G. Lin, "Optimal design of a multi-couple thermoelectric generator," Semiconductor Science and Technology, vol. 15, no. 2, pp. 184-188, 2000.
[30] M. Kubo, M. Shinoda, T. Furuhata, and K. Kitagawa, "Optimization of the incision size and cold-end temperature of a thermoelectric device," Energy, vol. 30, no. 11-12, pp. 2156-2170, 2005. 

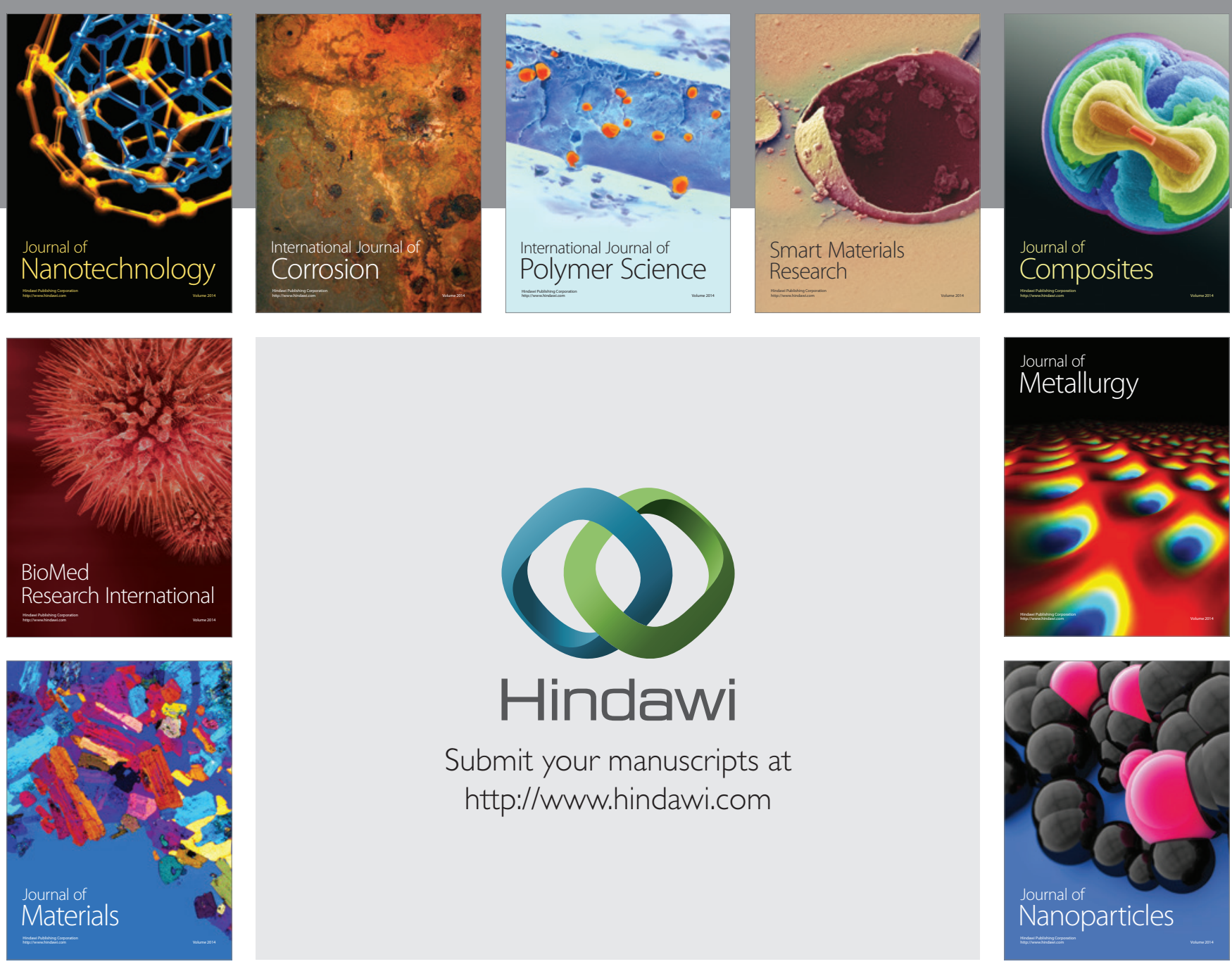

Submit your manuscripts at http://www.hindawi.com
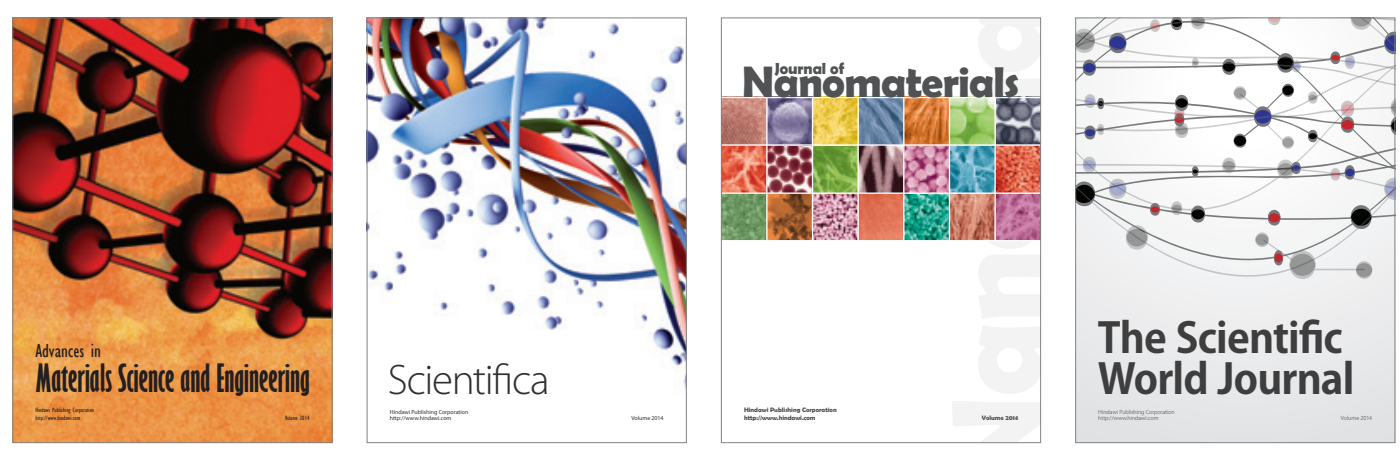

\section{The Scientific World Journal}
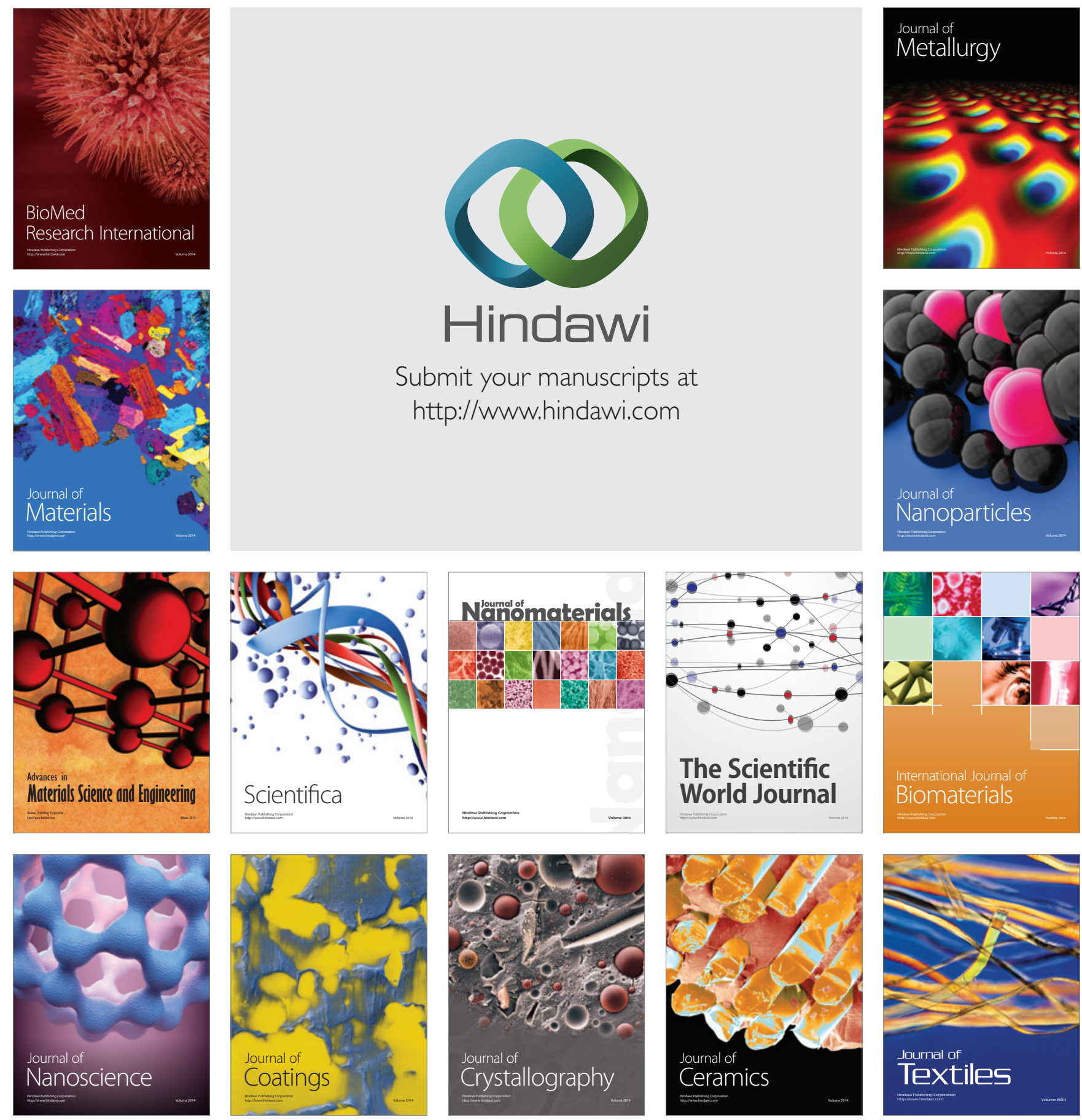